\title{
Soccer Syndrome - 3: Common Sacral Malalignments and Its Manual Diagnostic Techniques
}

\author{
Ganesh Elumalai ${ }^{1, ~ *, ~ A m e e t ~ K u m a r ~ J h a ~}{ }^{2}$, Palani Kanagarajan ${ }^{3}$, Sanjoy Sanyal ${ }^{4}$ \\ ${ }^{1}$ Department of Anatomy and Neuroscience, Texila American University, Georgetown, South America \\ ${ }^{2}$ Department of Anatomy, Texila American University, Georgetown, South America \\ ${ }^{3}$ Department of Community Medicine, Texila American University, Georgetown, South America \\ ${ }^{4}$ Department of Neuroscience, Texila American University, Georgetown, South America
}

\section{Email address:}

ganesh.e@tau.edu.gy (G. Elumalai), ameet.k@tau.edu.gy (A. Kumar Jha), palani.k@tau.edu.gy (P. Kanagarajan), sanjoy.s@tau.edu.gy (S. Sanyal)

\section{To cite this article:}

Ganesh Elumalai, Ameet Kumar Jha, Palani Kanagarajan, Sanjoy Sanyal. Soccer Syndrome - 3: Common Sacral Malalignments and Its Manual Diagnostic Techniques. American Journal of Sports Science. Vol. 4, No. 2, 2016, pp. 25-37. doi: 10.11648/j.ajss.20160402.12

\begin{abstract}
The present study was primarily focused to determine the common presentations and manual diagnostic procedures for sacral malalignments. Forty football players $(n=40)$, from National Football Club (NFC) were selected for the study. Subjects were constrained to males with no history of orthopedic or neurological issues, and also include the subjects only with normal muscle power and Range of movement (ROM) of the back and extremities. The mean age of the studied population was $22.2 \pm 3.9$ years, height $175.8 \pm 6.6 \mathrm{cms}$, and weight $87.5 \pm 7.1 \mathrm{kgs}$. The important bony landmarks like Sacral Sulci and Base, Infero-Lateral Angles (ILA) of sacrum, position of L5 vertebra and Sacrotuberous ligament were located manually. These landmarks were considered as an extremely basic and vital for the manual assessment of sacral malalignments. In this study, we observed, $50 \%$ i.e., majority of the soccer's were suffered with oblique axis malalignments, includes Right On Right - ROR and Left On Left - LOL of sacral dysfunctions. The players suffered with AP and Transverse axis of sacral malalignments were encountered up to $17.5 \%$ and soccer's who had the vertical axis malalignments was observed only in $7.5 \%$. However, this method of assessing the sacral malalignments until then not documented. In this sense, the current study was mainly focused on the assessment and documentation of the different common presentations in sacral malalignments, which are most common in soccer players. This simple method of evaluation is the literature state of the art. The present study may provide the useful informations to analyze the common presentations of sacral malalignments in different sports.
\end{abstract}

Keywords: Sacral Dysfunction, SI Joint Dysfunction, Low Back Pain, Pelvic Malalignments

\section{Introduction}

In the early twentieth century, sacroiliac (SI) joint disorders producing low back pain was the most widely recognized problem, which prompted that period being named as "Era of the SI Joint." Any torment emanating from the Lower back, Gluteal or adjacent leg was regarded as SI joint disorder. However, this generalization came into a sudden stop in 1934, when Jason Mixter published an article on intervertebral disc injury in "The New England Journal of Medicine" [18].

The SI joint unites the sacrum (triangular bone at the base of the spine) with the pelvis (iliac bone that is a component of the hip joint) on each side of the lower spine. It transmits all the forces from the upper body to the pelvis and legs. Because of its extremely solid architecture and stable configuration, it demonstrates insignificant range of movements $[23,17,10]$.

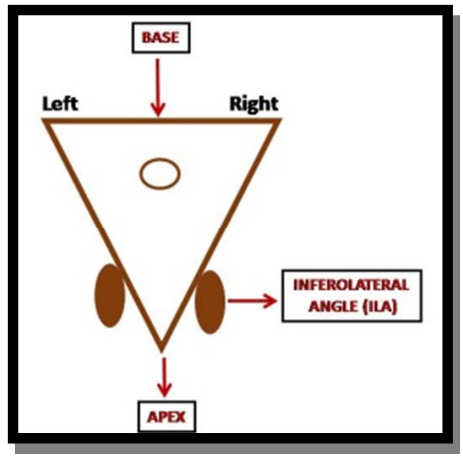

Fig. 1. Bony Sacrum. 
The sacrum is a large wedge shaped vertebra at the lower end of the spine. It shapes the solid base of the spinal column, where it intersects the hip bones to form the bony pelvis. The sacrum is an extremely solid bone that supports the weight of the upper body, as spreads across the pelvis and legs. The sacrum develops from five individual vertebrae which fuse to form a single bone at around the age of thirty. The tubercles along the posterior surface of the sacrum represent the spinous processes of the fused vertebrae.

The sacrum forms the fibro-cartilaginous joint with the fifth lumbar vertebra above and with the coccyx below. The sacroiliac joint was formed by the articulation of sacrum and ilium to complete the bony pelvis. Numerous ligaments firmly strap the sacroiliac joints together to balance out the bony pelvis, and also it decreases the movement of the joint $[5,6,15]$.

\section{MOVEMENTS OF SACRUM}

The sacrum moves in multiple axis at Sacroiliac and Lumbo- Sacral joints, it usually moves in relation with the Innominate and Lumbar bones [12].

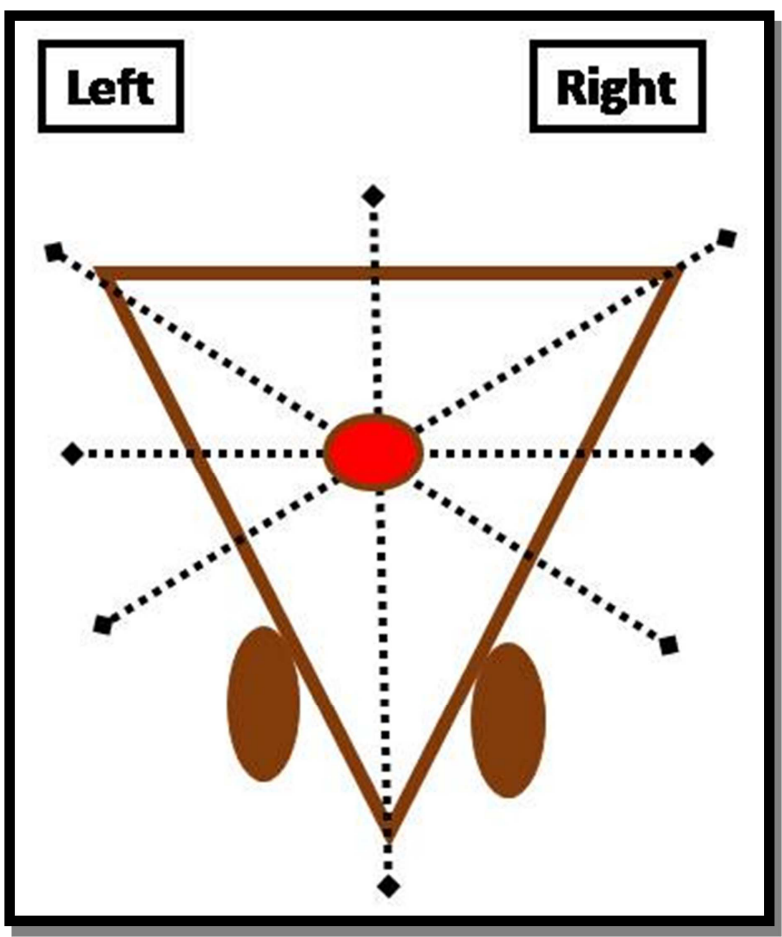

Fig. 2. Multiple Axis of Motion.

\section{A. Transverse}

- Superior - Physiological Axis (Respiratory)

- Middle - Postural Axis

- Inferior - Pelvic Axis

B. Vertical (sagittal)

C. Oblique

- Right Oblique axis

- Left Oblique axis

D. Antero-Posterior

II. Movements in Corresponding Axis:

A. Transverse: (Fig.-3 \& 4)

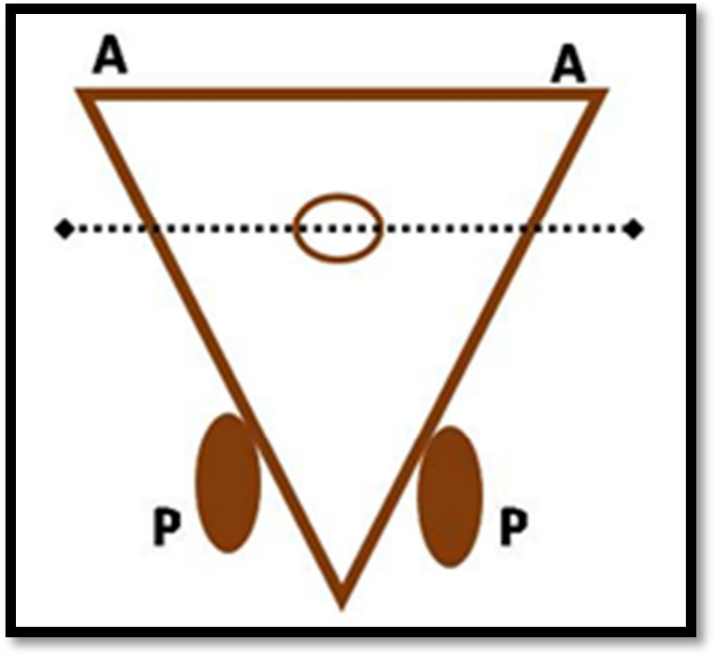

Fig. 3. Bilateral Nutation ( $A=$ Anterior; $P=$ Posterior $)$.

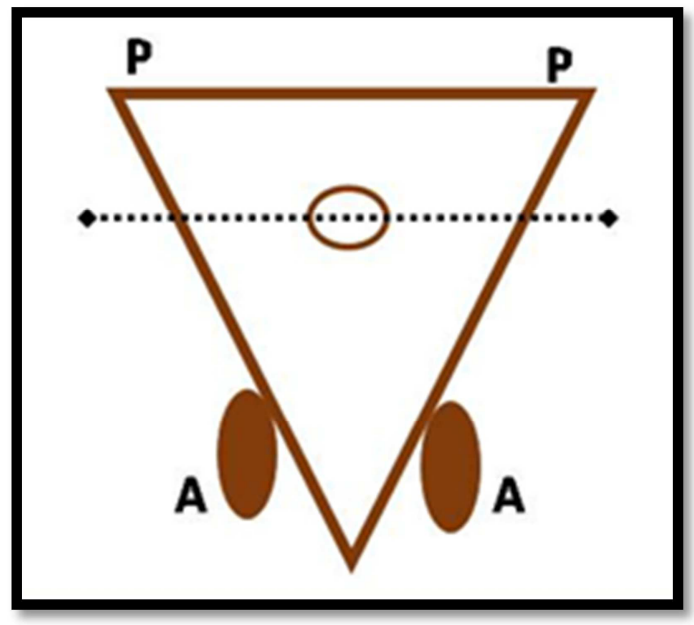

Fig. 4. Bilateral Counter-nutation (A=Anterior; $P=$ Posterior).

B. Vertical: (Fig.-5 \& 6)

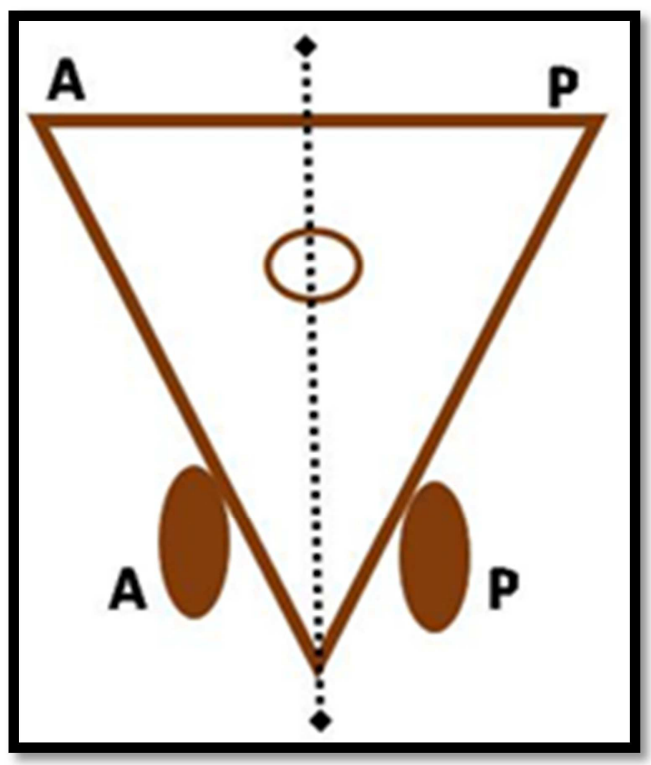

Fig. 5. Unilateral Nutation ( $A=$ Anterior; $P=$ Posterior $)$. 


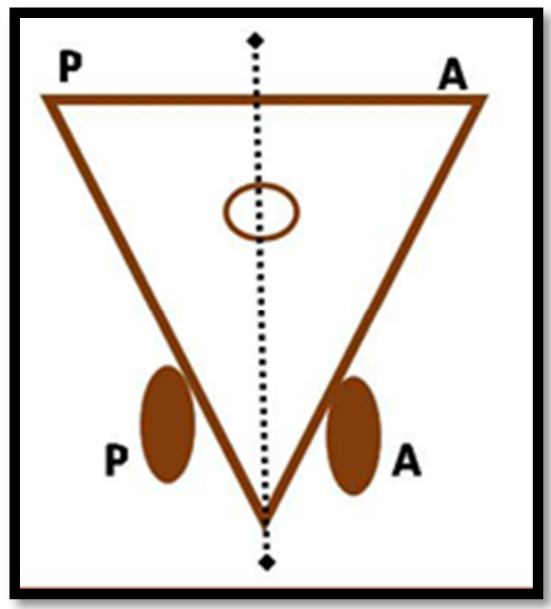

Fig. 6. Unilateral Counter-nutation ( $A=$ Anterior; $P=$ Posterior).

C. Oblique: (Fig.-7 \& 8)

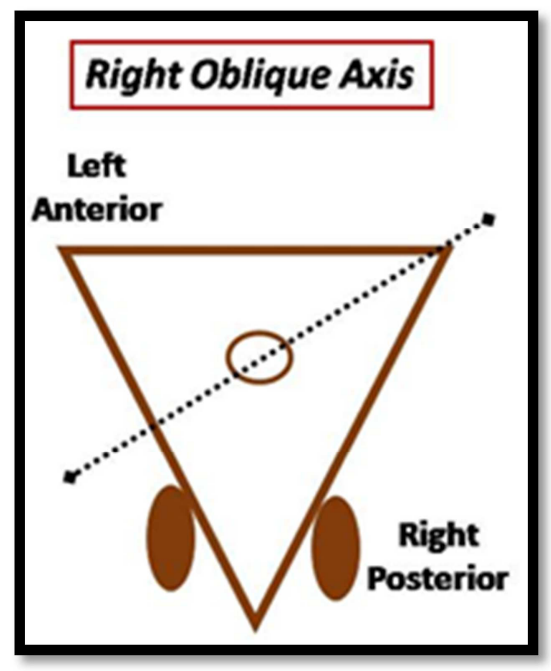

Fig. 7. Right Oblique axis.

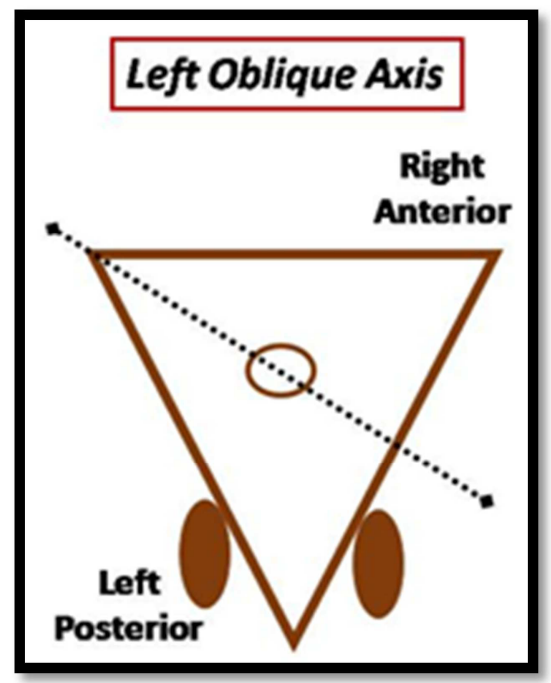

Fig. 8. Left Oblique axis.

D. Antero-Posterior: (Left on Right) (Fig.-9 \& 10)

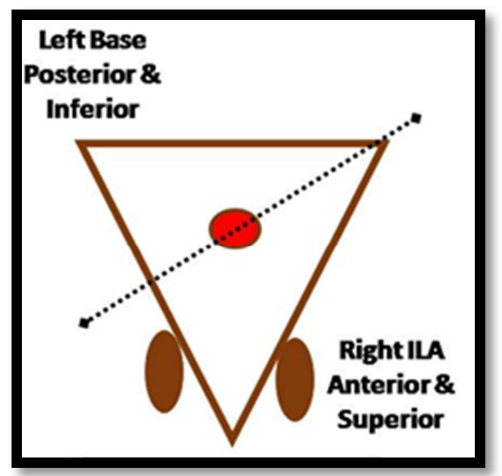

Fig. 9. Rotation in relation with Right Oblique axis Clockwise rotation.

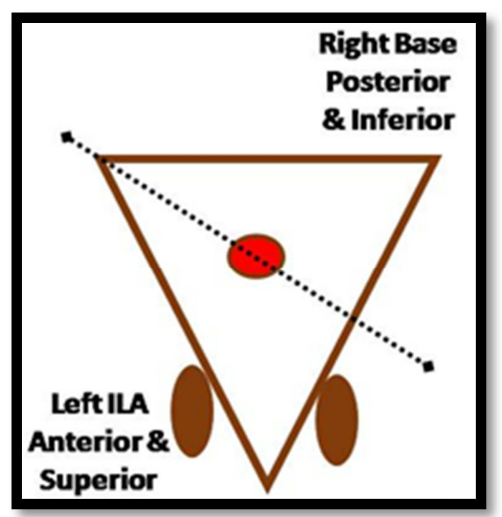

Fig. 10. Rotation in relation with Left Oblique axis Anti-Clockwise rotation.

MUSCLES RESPONSIBLE TO MAINTAIN THE SYMMETRY OF BONY SACRUM: (Fig.-11 \& 12)

The pathogenesis of SI joint dysfunction is poorly understood. The muscle instability causes the malalignment in the joint or the impairment in its normal movement patterns. The muscle imbalance may due to the tissues strained from abuse or under-use or misuse. SI joint dysfunction commonly produces the pain on one side low back or in the gluteal region. However, it is possibly because of the stuck or free course of action in the joint, it usually presents with an alternate form of inconvenience [1, 13, 19, 22]. As a result of little extent of SI joint movement, and its intrinsic biomechanical characteristics and multifaceted nature, the most ideal examination and conclusion of SI joint dysfunction is, best dubious [1, 13, 19, 22].

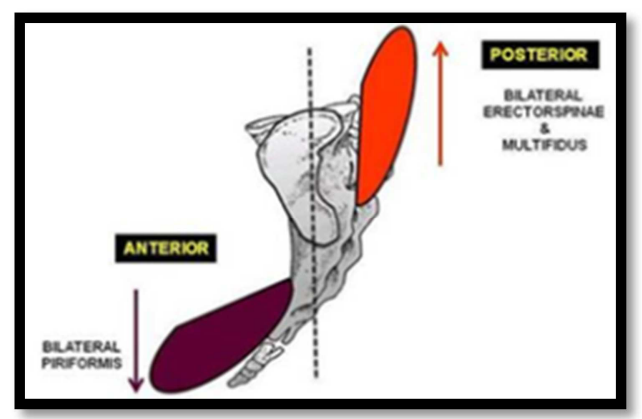

Fig. 11. Muscles responsible for symmetry of sacral bone in Transverse and vertical Axis. 


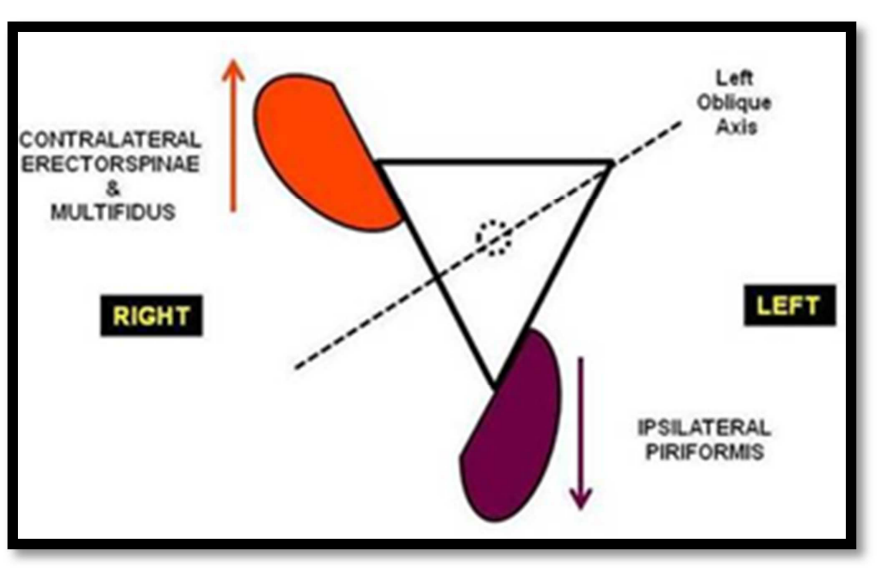

Fig. 12. Muscles responsible for symmetry of sacral bone in Oblique and AP Axis.

\section{Materials \& Methods}

All aspects of human care compiled with the ethical guidelines and technical requirements were approved by the Institutional Human Ethics Committee (IHEC) and Institutional Review Board (IRB). Forty football players ( $\mathrm{n}=$ 40) from National Football Club (NFC) were qualified for support in the study. Subjects were limited to men who had a normal muscle strength and range of Motion (ROM) of the back and lower extremities and no history of orthopaedic or neurologic disorders. The mean age of the study population was $22.2 \pm 3.9$ years, height $175.8 \pm 6.6 \mathrm{cms}$, and weight 87.5 $\pm 7.1 \mathrm{kgs}$. All subjects were instructed to restrict excessive physical activity on the day of testing, such as recreational running and bicycling, and to wear gym trunks for the tests. On the day of testing, all the subjects were reviewed and informed consent prior to precede the study.

During the assessment, we demonstrate to perform the movements to gain access the malalignments of the Sacrum. In addition, to justify our diagnosis we accessed the muscles of the functional slings and muscles related to the sacral malalignments $[8,9]$. We encouraged all the subjects to relax and not to inform them, that the movements would be judged as "good" or "bad." We believed these verbal cues decreased subjects' anxiety and, therefore, helped to standardize the testing. The techniques were repeated in different positions and also performed two times per day and continued for fifteen days to standardize [8].

\section{Assessment of Malalignments}

The sacral malalignments usually accompanied with the malalignment of Innominate and / or Lumbar vertebra [8, 9]. The initial steps in the diagnosis of malalignments were to identify the presence of asymmetry; this might be due to one or combination of the following:

A. An anatomical (true) leg length difference (LLD)

B. Presence of True or Compensated Trendelenburg's sign

C. Innominate malalignment

D. Sacral stuck
Examination was preferably carried out on a firm, even surface and in different postures like Standing, Sitting and Lying. Examination performed on a soft or sagging support or across a break in the surface (a feature common to medical plinths), may affect the assessment and lead to incorrect conclusions and possibly misdiagnosis. To correct the sacral malalignment, determination of the type of sacral malalignments were the utmost importance.

A. Measurement of Limb Length Discrepancies: (LyingSitting-Lying Test)

This was a quickest method to find out, whether malalignments were actually present or not. If present, it helps to find out the type of malalignments, 'rotational', 'upslip', 'flare' or a combination of these. The measurement of leg length is much easier and more accurate, by comparing the level of the thumbs placed in the hollow sulcus immediately below the medial malleolus on each side, directly overlying the medial ankle ligaments. Point the tip of each thumb straight downward (distal phalanx vertical) helps to compare the relative level of interphalangeal joints (i.e. knuckles) which end up closer together and are more clearly demarcated than the tip malleoli assessment, also it helps to make side-to-side comparison more accurate. Remember to hold onto the ankles lightly - the thumbs are only serving you as a guide to compare side-to-side leg movement and length on sitting and lying. A common mistake is to hold on forcefully, at the risk of impairing free upward and downward movement of the legs, making the person to actual discomfort. The person initially lies supine and is then asked to sit up. A shift of the pelvis or other error is less likely avoided (to prevent the activation of leg, pelvic or trunk muscles that can influence movement of the pelvis). Then the assessment is repeated with the supine lying, for comparison $[8,9]$.

Clinical Correlations:

1. When one leg is shorter by an equal amount in both sitting-up and lying-down

a 'true' LLD, with all the landmarks are aligned

b an 'upslip', with all the landmarks, both anterior and posterior, have moved upward on the side of the 'upslip'.

2. When leg length is equal

a pelvis is in alignment, with all the landmarks symmetrical

b presence of an 'outflare or inflare' malalignment

3. When leg length shifts

a suspect a 'rotational malalignment', with landmarks all asymmetrical. But,

b rule out the person is not sitting or lying slightly asymmetrically with a wallet or other object in a back pocket or on account of a break in the plinth.

B. Assessment of True or Compensated Trendelenburg's (Gait) Sign

Asymmetrical weight-bearing plays an important factor on account of an anatomical (true) or a functional leg length difference, attempting the pelvic girdle to compensate for problems to transfer load through the lumbo pelvic- hip 
complex in order to overcome the insufficiency $[8,9]$. It may be either by two ways

a) Compensated Trendelenburg's (sign) gait

If a person is with the weakness in the left hip abductors, it makes him difficult for stabilizing the left hip and SI joint for proper load transfer through the hip, SI joint and up through the lumbo-sacral junction (Fig.-13).

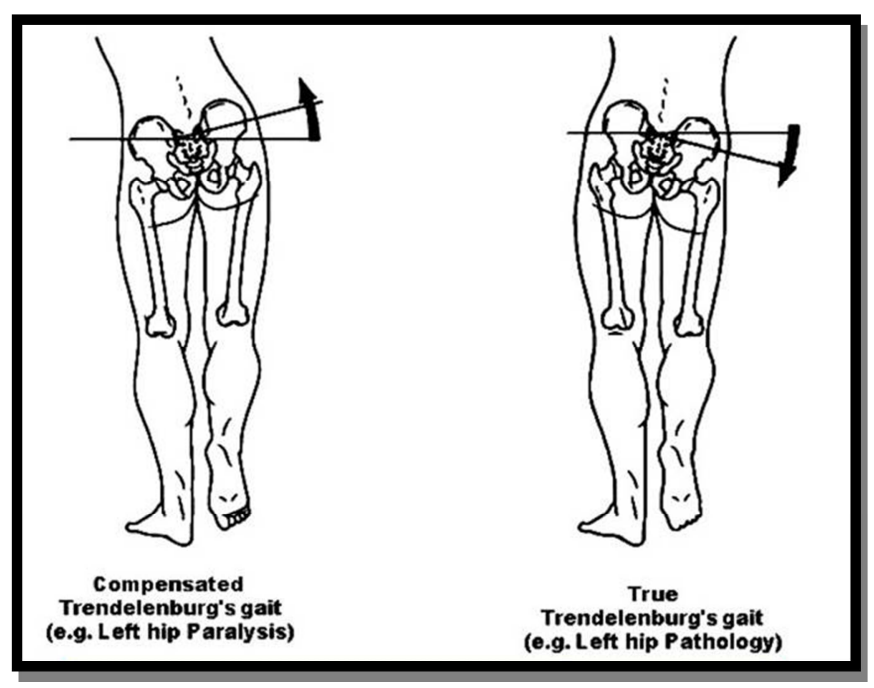

Fig. 13. True and Compensated Trendelenburg's (gait) sign.

When walking, the person compensates by leaning the trunk into the impaired left side during mid-stance, moving the centre of gravity outward from midline and more directly over top of the hip joint, thereby

- decreasing the need for left abductor muscle action to achieve stability of the left hip joint

- decreasing vertical shear forces through the left SI joint.

b) True Trendelenburg's (sign) gait

A person with the left hip instability caused by the degeneration (osteoarthritis) of the joint or by inflamed and painful joint will have difficulty in stabilizing the left hip and SI joint (Fig.-13). The person may compensate for the impaired ability to transfer load through the left hip by leaning away from that side (adducting the pelvis, abducting the left femur) in midstance, thereby

- bringing the centre of gravity closer to midline (away from the left hip joint and toward the SI joint)

- decreasing stress on the painful left hip joint

- depending more on the strong left hip abductors to ensure stability of the left hip joint and also of the pelvic unit.

\section{Common Innominate Malalignments}

The common presentations of innominate malalignments were appeared in isolation or in combination with one or both of the others. For example, an 'Upslip' appears about $10 \%$, in combination with either 'rotational malalignment' or 'flare' or both $10 \%$, and total of $20 \%$. Based on the past observation [9], the common 'Innominate malalignment' refers to fixation of an innominate bone relative to the sacrum in excessive anterior or posterior rotation in the sagittal plane [2]. Such rotation can affect an innominate on one side but it was more likely to seen in association with:

1. Compensatory rotation of the contralateral innominate around the coronal axis in the sagittal plane. (e.g. Right side anterior rotation with Left side Posterior rotation)

2. Compensatory rotation of the contralateral innominate around the vertical axis in the transverse plane. (e.g. Right side anterior rotation with outflare \& Left side Posterior rotation with inflare)

3. Upslip of innominate with the displacement of the pubic bone superiorly, relative to each other

4. Upslip with compensatory rotation of the contralateral innominate around the coronal axis in the sagittal plane. (e.g. Upslip \& Right side anterior rotation with Left side Posterior rotation)

5. Upslip with compensatory rotation of the contralateral innominate around the vertical axis in the transverse plane. (e.g. Upslip \& Right side anterior rotation with outflare \& Left side Posterior rotation with inflare)

6. Both the innominate in fixed with Anterior (Anteriortilt), Posterior (Posterior-tilt) and Lateral (Lateral-tilt, without the displacement of the pubic bone superiorly).

D. Assessment of Sacral Alignments

It was essential to locate the following landmarks to judge the alignments of bony sacrum:

- Posterior superior iliac spines (PSIS)

- Sacral Sulci \& Base

- Infero-Lateral Angles (ILA) of the sacrum

- Sacrotuberous ligament and

- Position of L5 vertebra

a. Palpation of Sacral Sulci \& Base: (Fig.: 14 - 18)

The palpation of sacral sulci \& base were performed at Lumbo-Sacral junction. We checked the shallow or depth orientation of the sacral sulci with the thumb and sacral base with the index finger. We palpated the groove just medial to PSIS (space between sacral spines and parallel sacral crest), and measured the depth of the sacral sulci on both the sides. We compared the presentation, whether it was shallow or deep and more anterior or posterior. We brought the index finger over the sacral base and recorded the base either anterior or posterior or equal.

b. Palpation of Infero-Lateral Angle (ILA):

We placed the pads of the thumbs over the sacrum, close to its caudal end and recognized the coccyx. We Kept the thumbs one inch apart from the midline and pushed towards the cephalad until the cushions laid on the inferior margin of ILAs and carefully read the relative position of ILAs, whether it was inferior or superior or conceivably even. We placed the pads of the thumbs over the posterior surface of the ILAs, and used moderate pressure to judge the orientation of anterior or posterior or equal.

\section{c. Palpation of Sacrotuberous ligament:}

We placed the pads of both the thumbs on the inferior margin of ILAs and moved the thumbs infero-laterally from the ILAs. We pressed the thumbs antero-superiorly at $45^{\circ}-$ $50^{\circ}$ angles, to check the Sacrotuberous ligaments. The Presentation might be, equal in tension or tight or imprecise. 


\section{d. Palpation of L5 vertebra:}

The preferential movements of L5 vertebra were side bend and rotation. We located the L5 spinous process, and placed the pads of the thumbs over the tips of L5 transverse process. We noted the relative positions of the tips of L5 transverse process, and examined the presentation as superior or inferior, anterior or posterior. We observed the side bend and rotation of L5 using the same landmarks. The preferable presentations of L5 side bends towards right or left, or no side bend with or without marked rotational malalignments.

\section{Common Scaral Malalignments}

It was essential to locate the posterior superior iliac spines (PSIS), to judge the alignment of the sacrum. It was significant to recognize the relative position of Sacral Sulci and Base, Infero-Lateral Angles (ILA) of the sacrum, position of L5 vertebra and texture of the Sacrotuberous ligament to judge the type and side of malalignments of the sacrum.

\section{Mobility Test to Identify the Sacral Malalignments}

\section{Standing trunkflexion test: (Fig.-14\& 15)}

We ensured the presence of hamstring tightness or functional leg length difference (LLD) before this test. During the test we observed initially, the sacrum experienced the "Nutational movement" in the mid-range of trunk flexion, then the Interosseus, Sacrotuberous and Sacro-spinous ligaments were tightened, which derives the sacrum turned towards the "Counter-Nutation".

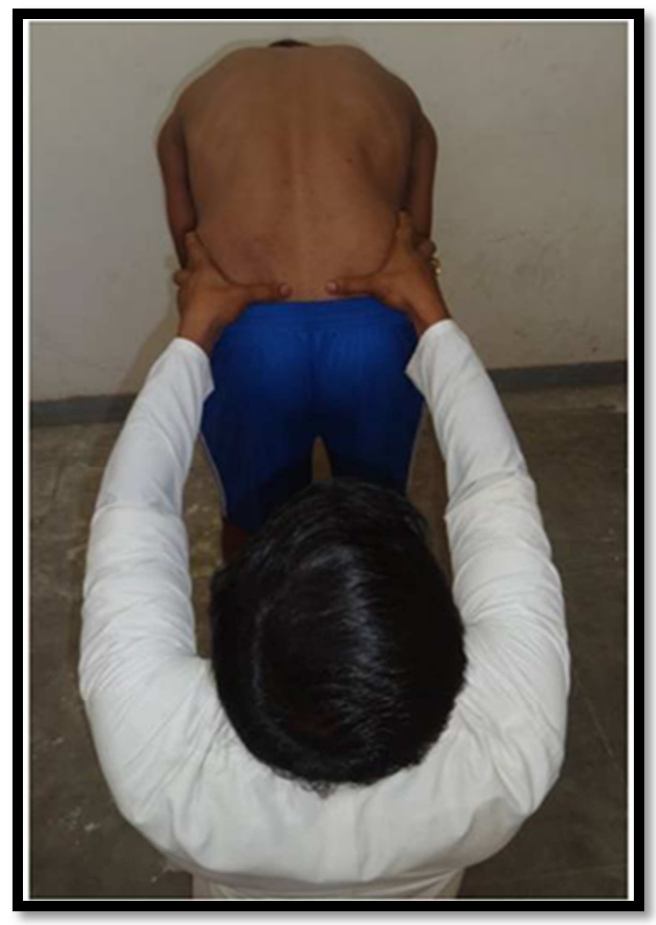

Fig. 14. Standing Trunk Flexion test - from behind.

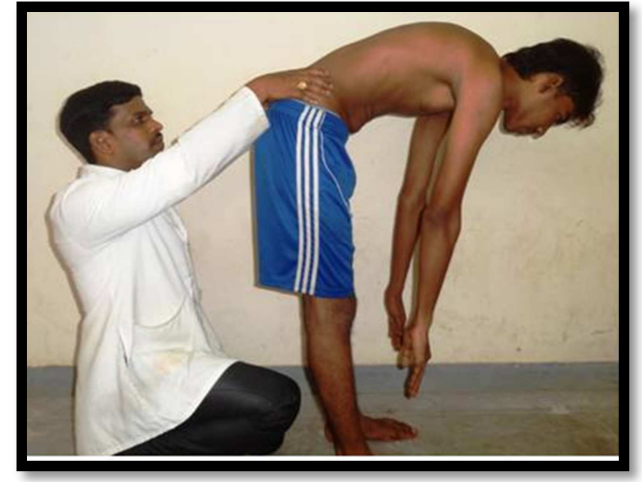

Fig. 15. Standing Trunk Flexion test-from side.

\section{Sitting trunk flexion test: (Fig.-16)}

During this test, the sacrum experienced "CounterNutation" at initial, which caused the tightness of "Long Dorso-Sacroiliac ligament". In the mid-range of seated trunk flexion test, the innominate experiences the posterior rotational movement, which leads the sacrum for 'Nutational alignment'.

III. Standing single leg flexion test: (Fig.-17)

This test were the most accurate assessment to differentiate the rotational stuck of sacrum either in AP, oblique or vertical axis (Fig.-30).

IV. Backward bending test: (Fig.-19)

During the assessment, the subject made to lay down to prone on the firm bed; the pads of the thumbs maintained the position on sacral sulci and base. Patients were allowed to bend backwards; the outcomes of this test were shown in the Fig.-19. (? = Extremely rare incidence)

V. Sacral Spring Test: (Fig.-20)

We made the subject to lie down in prone position, and placed the heel of one hand over the dorsal surface of the Sacrum and reinforced with the heel of other hand. We maintained the arms straight and incline to the body using the gentle vertical thrust; we produced the springing movements on sacrum for several (5-6 reps) times. The limitation to springing against the vertical thrust was Positive (absent or restricted springing), while the other was Negative (movement felt at joint).

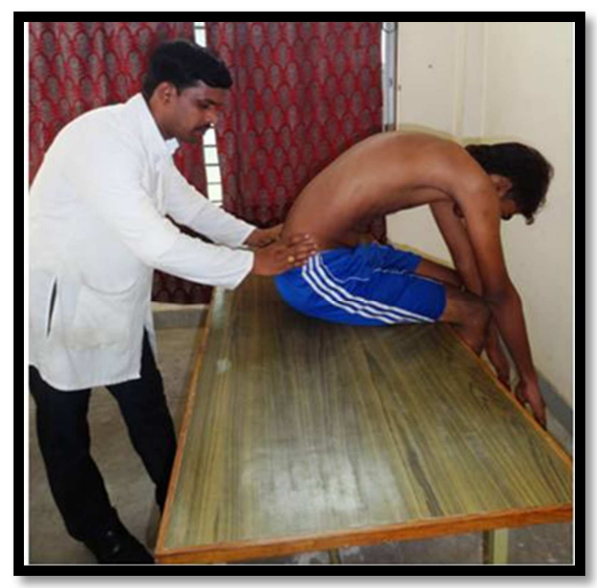

Fig. 16. Seated Trunk Flexion test. 


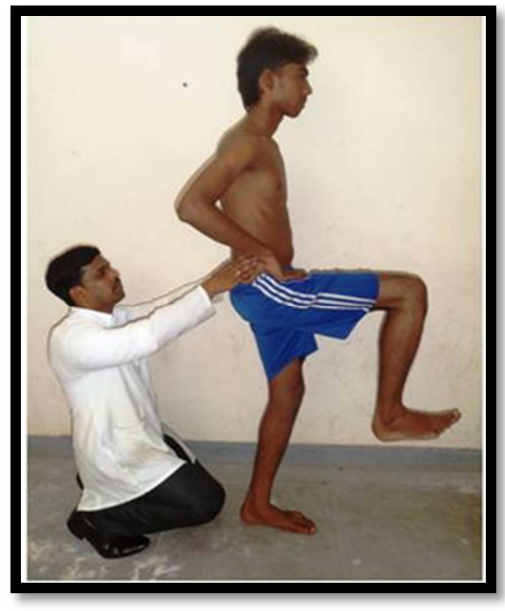

Fig. 17. Standing Single Leg Flexion test.

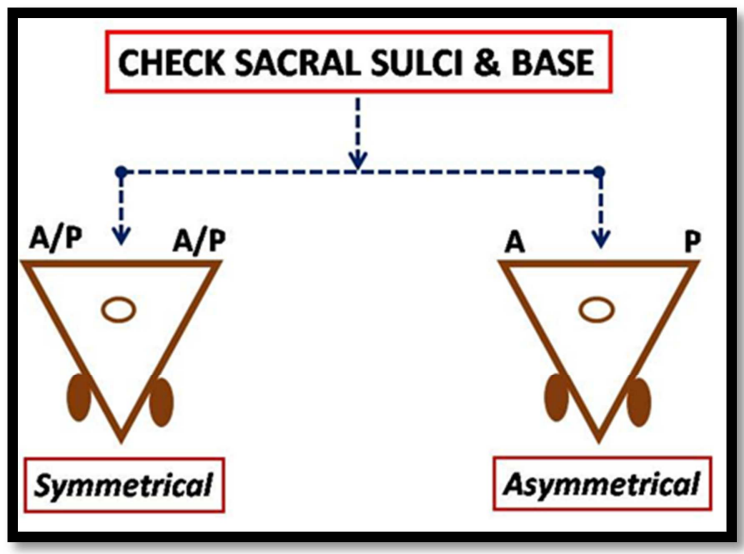

Fig. 18. Result of sacral sulci and Base assessment.

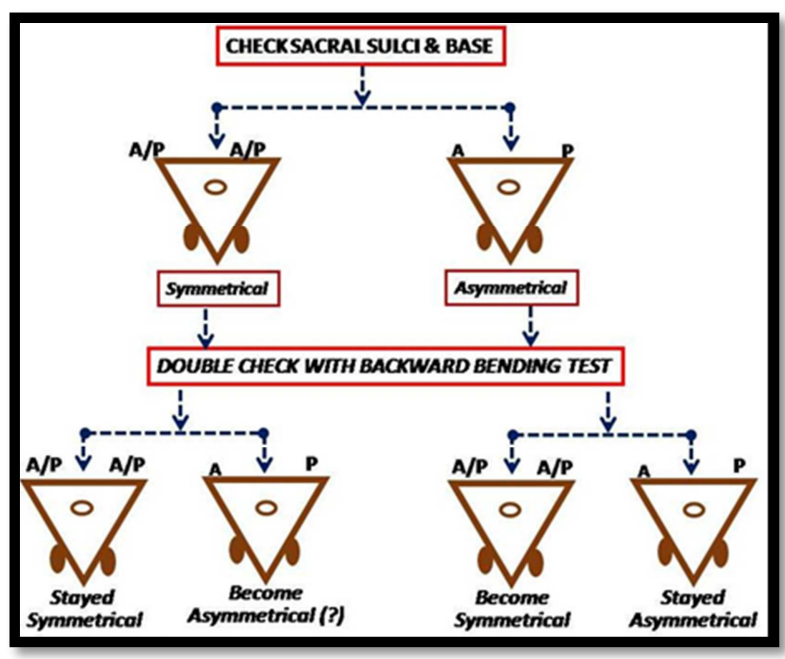

Fig. 19. Result of Backward bending test.

The negative test excluded the Bilateral CounterNutational stuck, however it uncovers the information of Neutral and Bilateral Nutational stuck of the sacrum (Fig.21). The later might be confirmed by the positive (secondary) seated trunk flexion test.

VI. L5 ASSESMENT: (Fig.-22).
The preferential movements of L5 vertebra were side bend and rotation. We located the L5 spinous process, and placed the pads of the thumbs over the tips of L5 transverse process. We noted the relative positions of the tips of L5 transverse process, and examined the presentation as superior or inferior, anterior or posterior. We observed the side bend and rotation of L5 using the same landmarks. The preferable presentations of L5 side bends towards right or left, or no side bend with or without marked rotational malalignments.

The possible dysfunctions of L5 were:

A. Neutral-Rotation-Side bending (NRS type)

B. Non -neutral-Rotation-Side bending (FRS \& ERS)

Neutral-Rotation-Side bending: (NRS type). (Fig-23 \& 24)

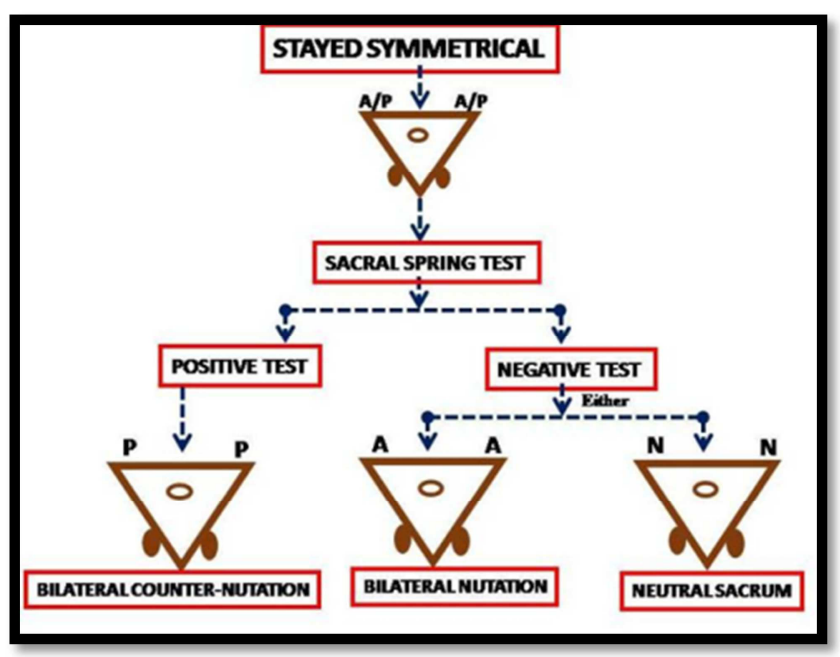

Fig. 20. Result of sacral spring assessment.

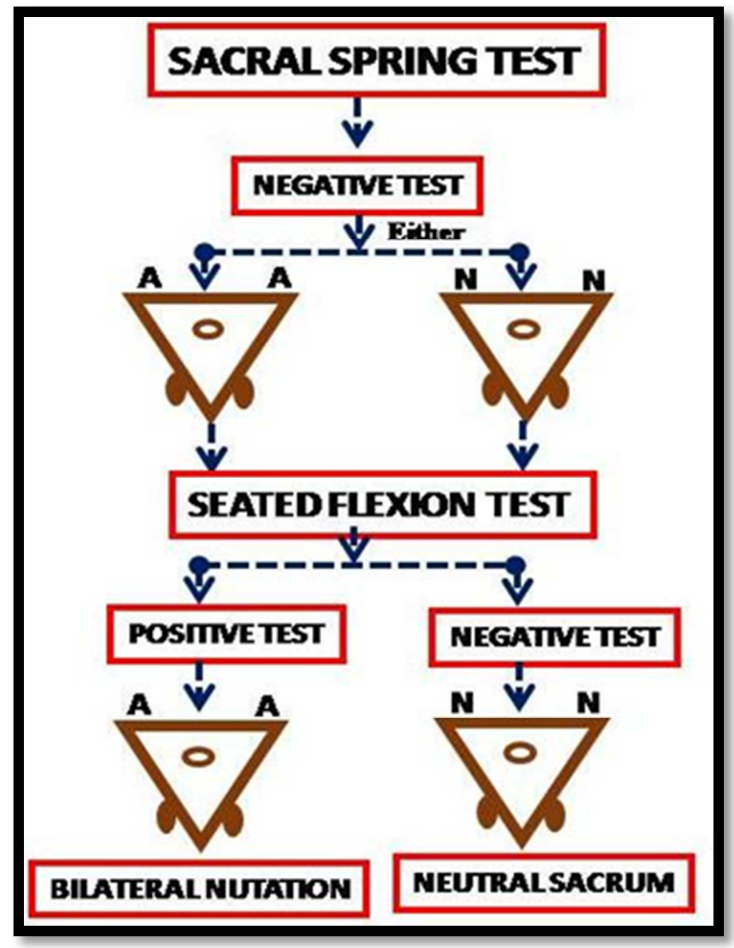

Fig. 21. Result of Secondary Seated Trunk Flexion test. 
In neutrally positioned spine, if the L5 rotated at vertical axis, the side bends happens at sagittal axis. The sacrum rotates same side oblique axis with "L5 side bend", and rotates towards opposite side with the "L5 rotation". The Neutral type dysfunctions were

i. $\quad$ Neutral, Rotated right and Side bend left $\left(N R_{R} S_{L}\right)$

In this type, the sacrum were stucked in Neutral, Rotated to Left with the Left Oblique axis. (LOL)

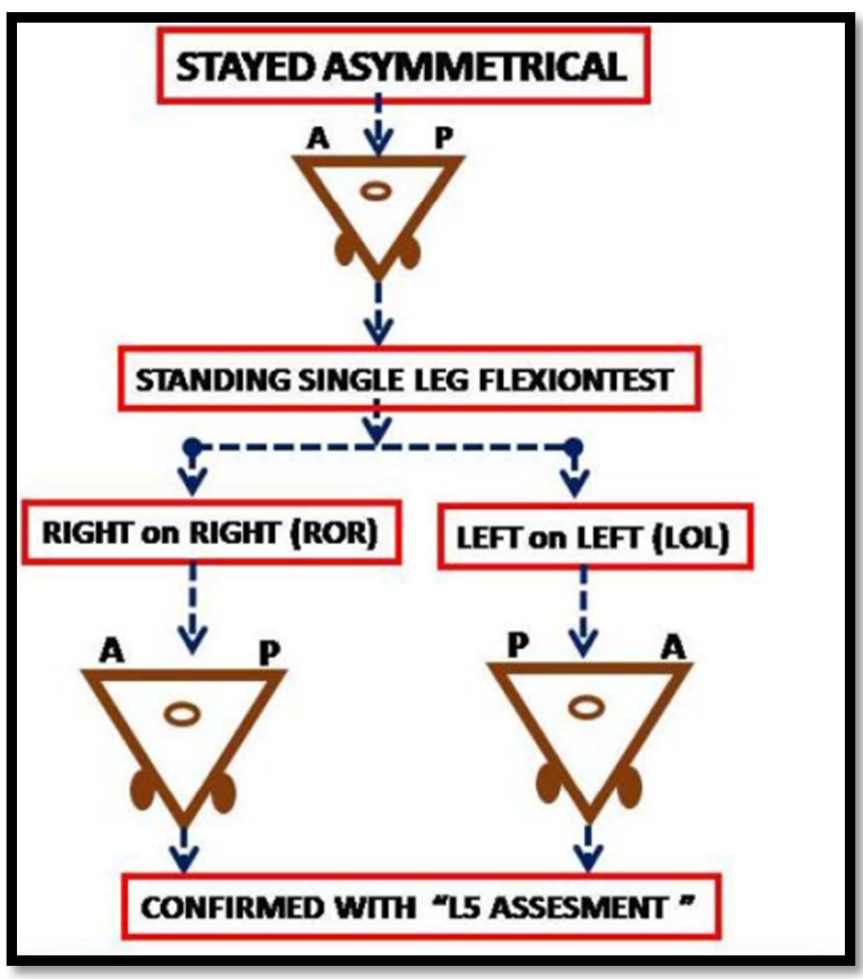

Fig. 22. Assessment of Stayed Asymmetrical Alignment.

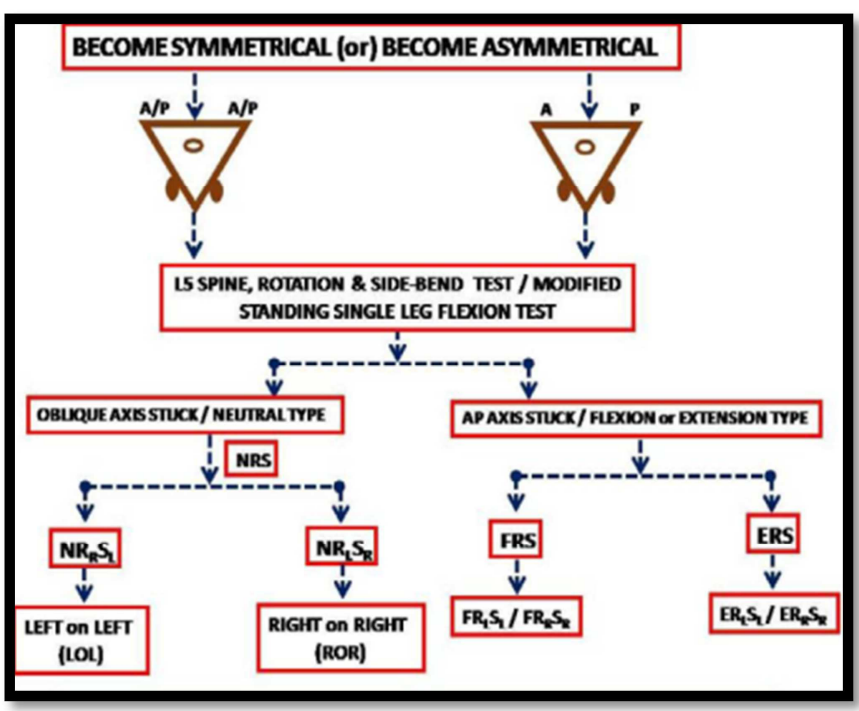

Fig. 23. Assessment of Become Symmetrical and Become Asymmetrical Alignment.

ii. Neutral, Rotated left and Side bend right $\left(N R_{L} S_{R}\right)$

In this type, the sacrum were stucked in Neutral, Rotated to Right with the Right Oblique axis. (ROR)

As a result, the NRS type dysfunction of L5, uncover the data of Oblique axis stuck of the Sacrum.

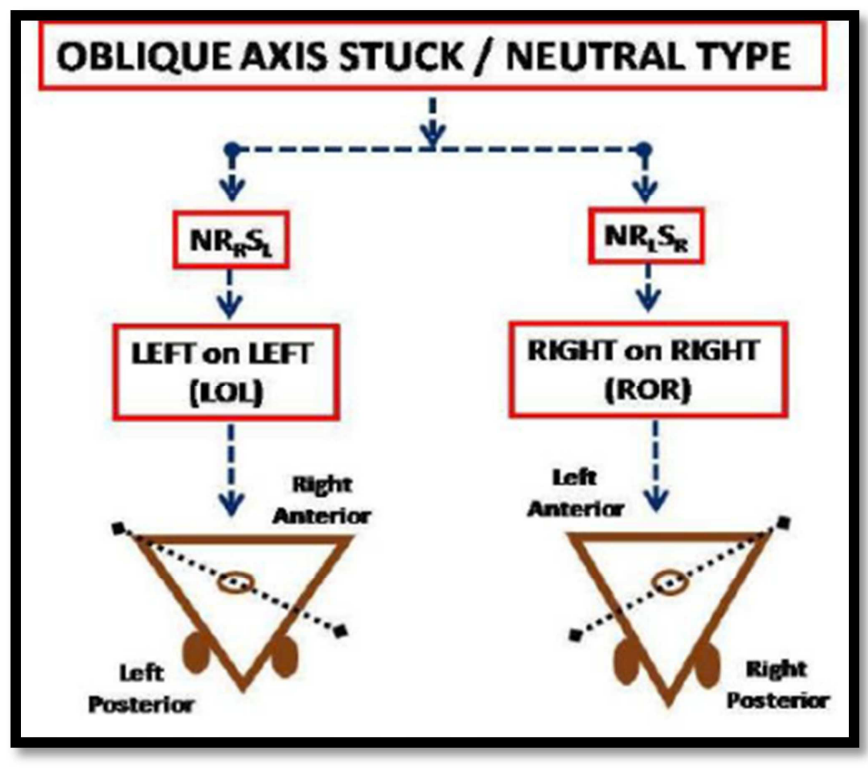

Fig. 24. Oblique axis stuck of sacrum.

In some cases, by the presence of L5 neutral position, with no rotatory and side bend malalignments, it fails to through the informations about sacral malalignments. In this situation, we need to relate the sacral base landmarks with ILAs positions. There might be a possibility in Unilateral rotational stuck of sacrum, in its vertical axis. It was affirmed by the assessment of the relative positions of sacral base and ILAs and correlates the results with standing single leg flexion test. (Fig.-25 \& 26)

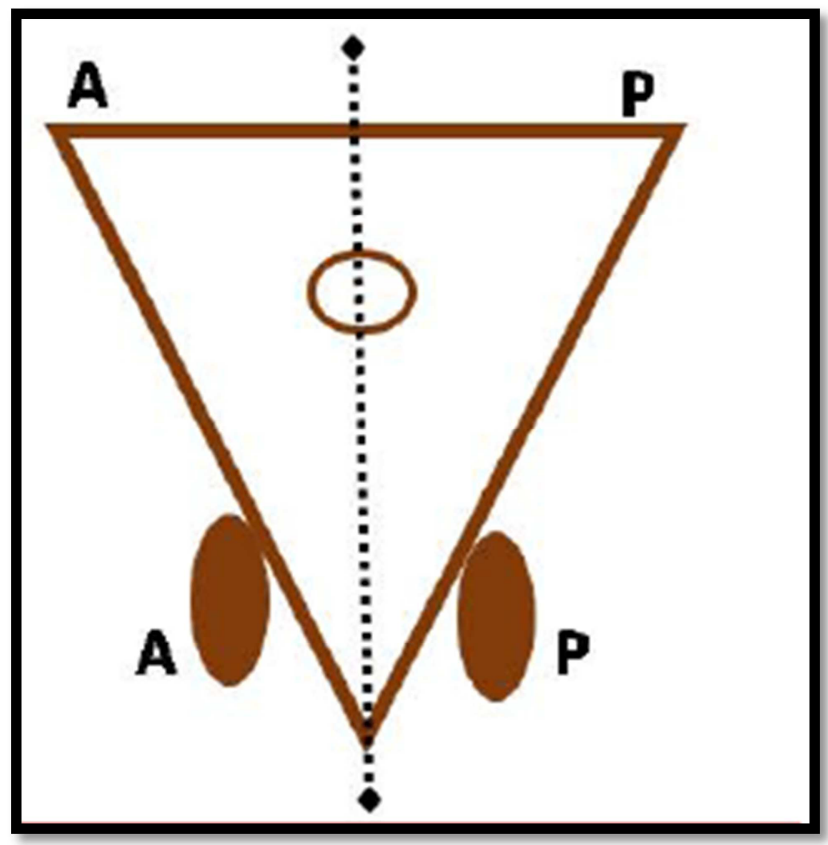

Fig. 25. Right Unilateral Nutational Stuck( $A=$ Anterior; $P=$ Posterior $)$. 


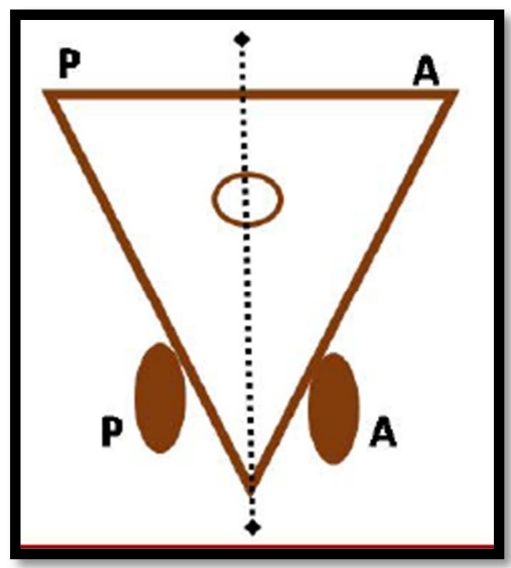

Fig. 26. Right unilateral Counter-Nutational Stuck(A=Anterior; $P=$ Posterior $)$.

Non-neutral-Rotation-Side bending: (FRS \& ERS type)

Normally in Non-neutral spine of L5, the Rotation \& Side bending in L5 occurs in same side. According to our above observations, the sacrum rotates same side oblique axis with "L5 side bend", and rotates towards opposite side with the "L5 rotation". Usually, in Non-neutral-Rotation-Side bending type of L5, the rotational stuck of sacrum occurs in AP axis rather than Oblique axis. The backward movement of the sacral base beyond the PSIS was usually not possible due to its hard end-feel. Example, the right sacral base fails to move beyond the right innominate PSIS, due to its hard end-feel. Therefore, the possible rotational dysfunctions of the sacrum in connection to the Non-neutral type (FRS and ERS) of L5 were possible only in AP axis either in clockwise and anticlockwise in course.

The sacrum rotates in clockwise or anti- clockwise course in relation to the L5 side bend. The right L5 side bend makes rotational stuck of sacrum in AP axis called "Clockwise rotational stuck". On the off chance, the left L5 side bend makes the rotation of sacrum in AP axis called "Anticlockwise rotational stuck".

The sacral dysfunctions usually occur in opposite side sacral base, in relation to the laterality of L5 rotational dysfunction. The right rotated L5 source left sacral base dysfunction. Similarly, the left rotated L5 produce the right sacral base dysfunction.

The Flexed type dysfunctions are

a Flexion, Rotated right and Side bend right $\left(F R_{R} S_{R}\right)$ (Fig.-27 \& 28)

Counter-Nutated stuck involved Left sacral base with Clockwise rotational stuck in AP axis. (LCC - Left, CounterNutated Clockwise stuck).

$b$ Flexion, Rotated left and Side bend left $\left(F R_{L} S_{L}\right)$ (Fig.$27 \& 28)$

Counter-Nutated stuck involved Right sacral base with Anti-clockwise rotational stuck in AP axis, (RCA - Right, Counter-Nutated Anti-clockwise stuck).

The FRS type dysfunction of L5 was demonstrated the Counter-Nutated stuck of the Sacrum in AP axis.

The Extension type dysfunctions are (Fig.-29)

a Extension, Rotated right and Side bend right $\left(E R_{R} S_{R}\right)$

Counter-Nutated stuck included Left sacral base with Clockwise rotational stuck in AP axis. (LNC - Left, Nutated, and Clockwise stuck).

$b$ Extension, Rotated left and Side bend left $\left(E R_{L} S_{L}\right)$

Counter-Nutated stuck included Right sacral base with Clockwise rotational stuck in AP axis (RNA - Right, Nutated, and Anti- clockwise stuck).

Consequently, the ERS type dysfunction of L5 will displays the Nutated stuck of the Sacrum in AP axis.

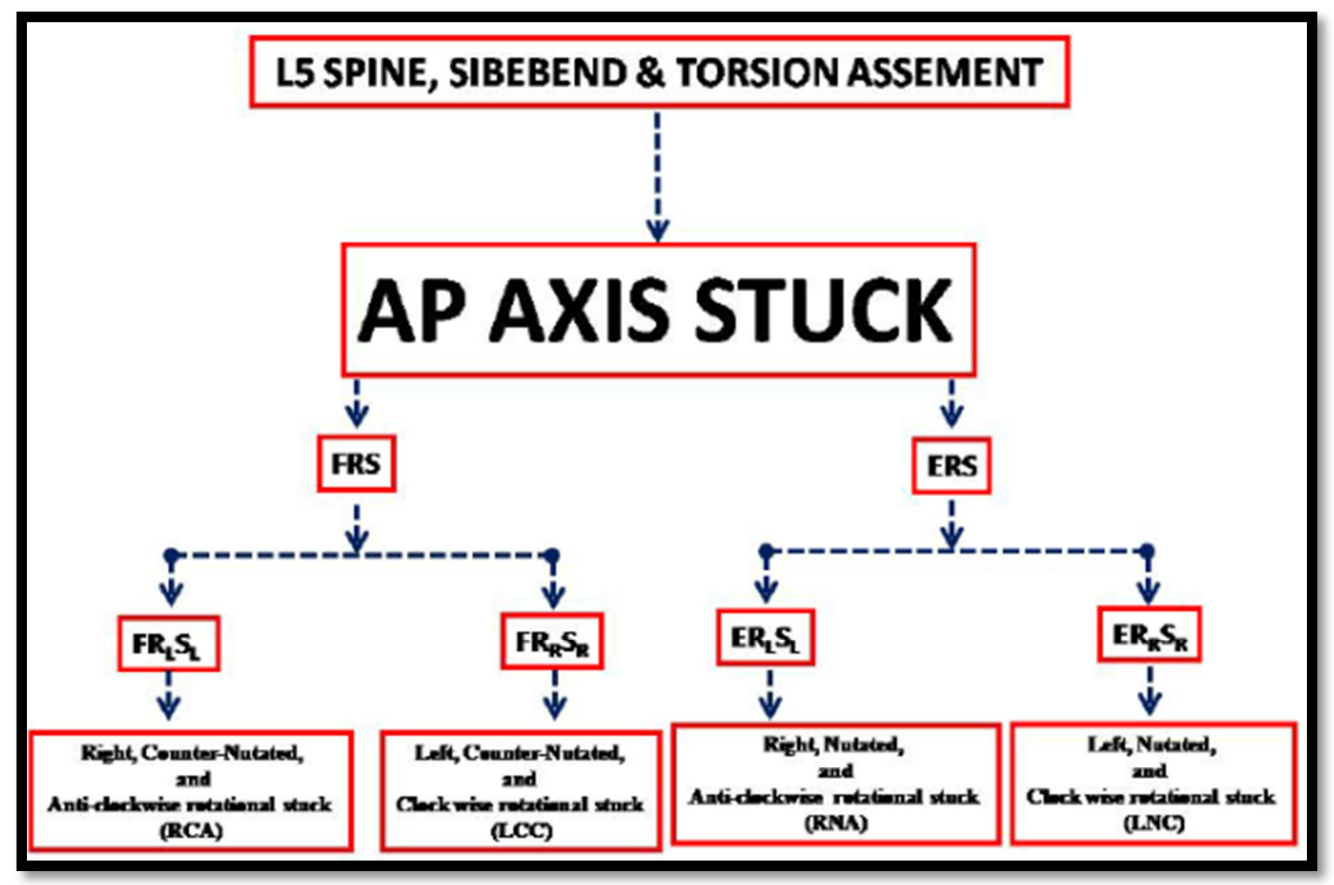

Fig. 27. AP axis Stuck in sacrum. 


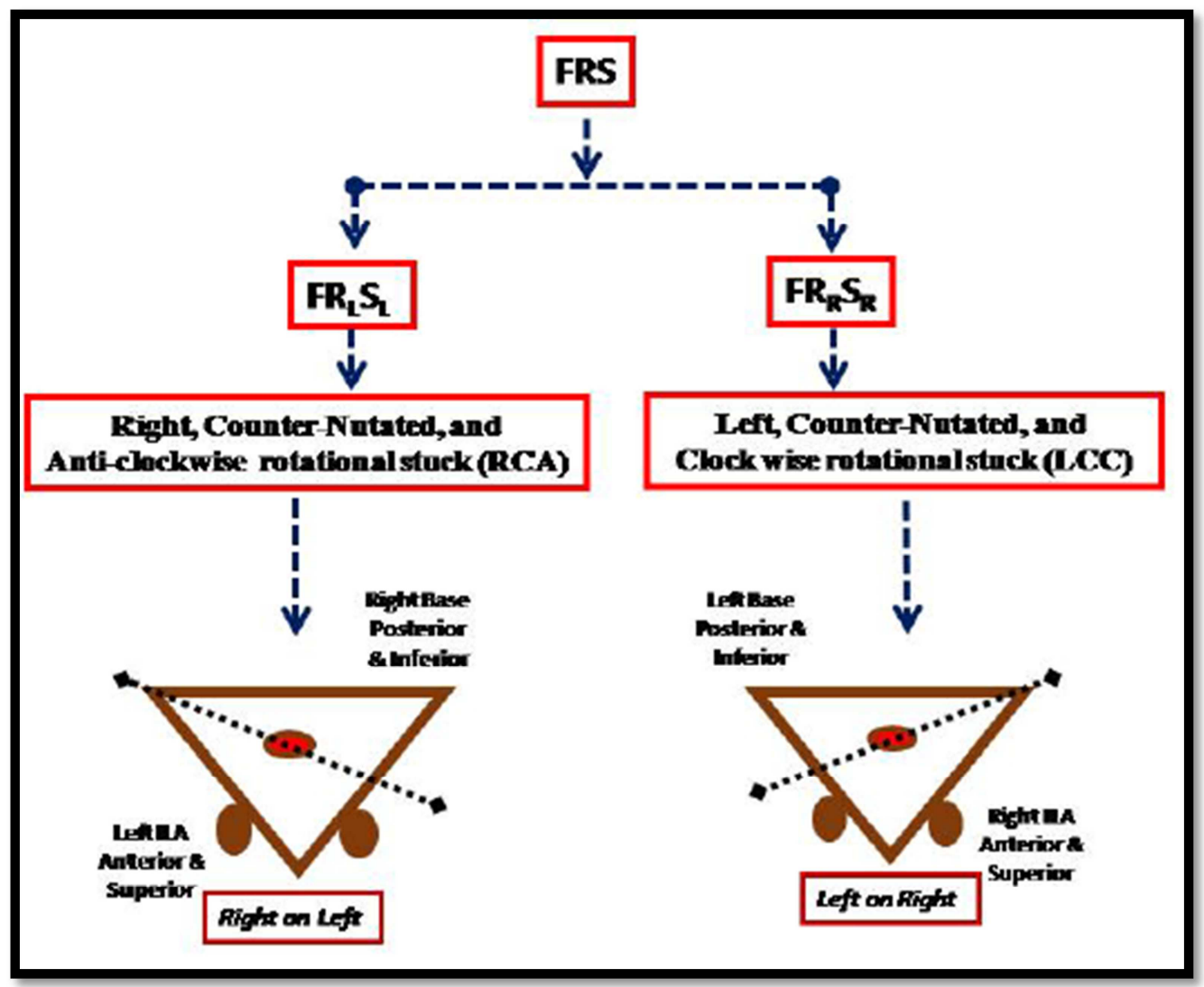

Fig. 28. AP axis Stuck in sacrum with flexed L5.

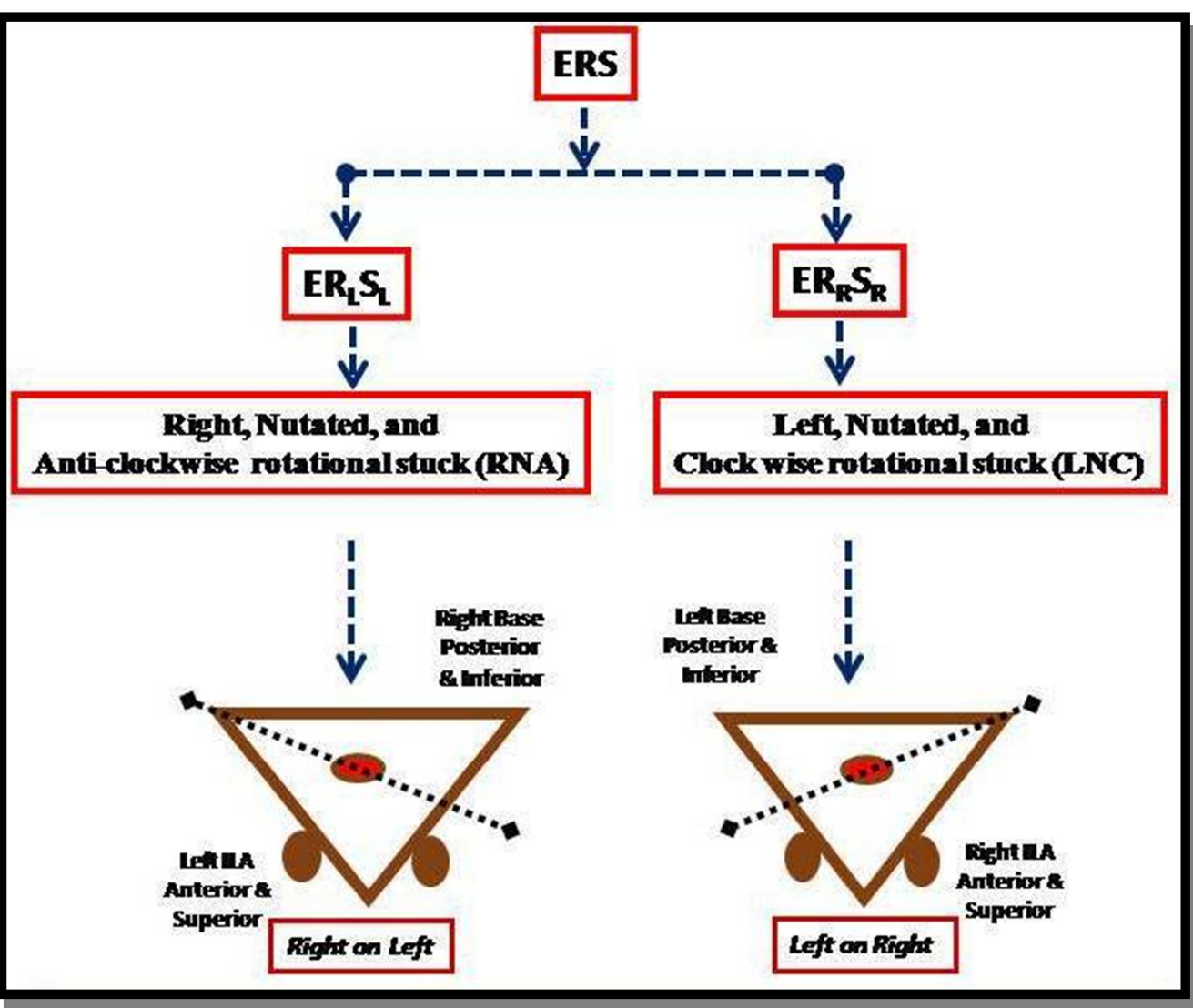

Fig. 29. AP axis Stuck in sacrum with Extended L5. 


\section{Reports: (Table-1 \& 2)}

Table 1. Period - 1 (Start of Preseason-3).

\begin{tabular}{|c|c|c|c|}
\hline S.NO & Sacral Malalignments & $\begin{array}{l}\text { Frequency } \\
(n=40)\end{array}$ & $\begin{array}{l}\text { Percentage } \\
(\%)\end{array}$ \\
\hline 1 & Bilateral Counternutational stuck & 0 & 0 \\
\hline 2 & Bilateral Nutational stuck & 1 & 2.5 \\
\hline 3 & $\mathrm{NR}_{\mathrm{L}} \mathrm{S}_{\mathrm{R}}$ (Right On Right - ROR) & 2 & 5 \\
\hline 4 & $\mathrm{NR}_{\mathrm{R}} \mathrm{S}_{\mathrm{L}}$ (Left On Left - LOL) & 3 & 7.5 \\
\hline 5 & Unilateral Nutational stuck & 1 & 2.5 \\
\hline 6 & Unilateral Counternutational stuck & 2 & 5 \\
\hline 7 & $\begin{array}{l}\mathrm{FR}_{L} \mathrm{~S}_{\mathrm{L}} \text { (Right Counternutational stuck } \\
\text { with Anticlockwise rotation - RCA) }\end{array}$ & 1 & 2.5 \\
\hline 8 & $\begin{array}{l}\mathrm{FR}_{\mathrm{R}} \mathrm{S}_{\mathrm{R}} \text { (Left Counternutational stuck } \\
\text { with Clockwise rotation - LCC) }\end{array}$ & 0 & 0 \\
\hline 9 & $\begin{array}{l}\mathrm{ER}_{\mathrm{L}} \mathrm{S}_{\mathrm{L}} \text { (Right Nutational stuck with } \\
\text { Anticlockwise rotation - RNA) }\end{array}$ & 1 & 2.5 \\
\hline 10 & $\begin{array}{l}\mathrm{ER}_{\mathrm{R}} \mathrm{S}_{\mathrm{R}} \text { (Left Nutational stuck with } \\
\text { Clockwise rotation - LNC) }\end{array}$ & 2 & 5 \\
\hline 11 & Neutral Sacrum & 27 & 67.5 \\
\hline TOTAL & & 40 & $100 \%$ \\
\hline
\end{tabular}

Table 2. Period - 2 (End of Preseason-3).

\begin{tabular}{llll}
\hline S.NO & Sacral Malalignments & $\begin{array}{l}\text { Frequency } \\
(\mathbf{n = 4 0 )}\end{array}$ & $\begin{array}{l}\text { Percentage } \\
(\mathbf{\%})\end{array}$ \\
\hline 1 & Bilateral Counternutational stuck & 3 & 7.5 \\
2 & Bilateral Nutational stuck & 4 & 10 \\
3 & $\mathrm{NR}_{\mathrm{L}} \mathrm{S}_{\mathrm{R}}$ (Right On Right - ROR) & 11 & 27.5 \\
4 & $\mathrm{NR}_{\mathrm{R}} \mathrm{S}_{\mathrm{L}}$ (Left On Left - LOL) & 9 & 22.5 \\
5 & Unilateral Nutational stuck & 1 & 2.5 \\
6 & Unilateral Counternutational stuck & 2 & 5 \\
\hline
\end{tabular}

\begin{tabular}{llll}
\hline S.NO & Sacral Malalignments & $\begin{array}{l}\text { Frequency } \\
(\mathbf{n = 4 0 )}\end{array}$ & $\begin{array}{l}\text { Percentage } \\
(\%)\end{array}$ \\
\hline 7 & $\begin{array}{l}\text { FR }_{\mathrm{L}} \mathrm{S}_{\mathrm{L}} \text { (Right Counternutational stuck } \\
\text { with Anticlockwise rotation - RCA) }\end{array}$ & 1 & 2.5 \\
8 & $\begin{array}{l}\mathrm{FR}_{\mathrm{R}} \mathrm{S}_{\mathrm{R}} \text { (Left Counternutational stuck } \\
\text { with Clockwise rotation - LCC) }\end{array}$ & 3 & 7.5 \\
9 & $\begin{array}{l}\text { ER } \mathrm{S}_{\mathrm{L}} \text { (Right Nutational stuck with } \\
\text { Anticlockwise rotation - RNA) }\end{array}$ & 1 & 2.5 \\
10 & $\begin{array}{l}\text { ER } \mathrm{R}_{\mathrm{R}} \text { (Left Nutational stuck with } \\
\text { Clockwise rotation - LNC) }\end{array}$ & 2 & 5 \\
11 & Neutral Sacrum & 3 & 7.5 \\
TOTAL & & 40 & $100 \%$ \\
\hline
\end{tabular}

\section{Discussion}

The present study, (Table $1 \& 2$ ) were observed $27.5 \%$ i.e., most of the soccer's are enduring with $\mathrm{NR}_{\mathrm{L}} \mathrm{S}_{\mathrm{R}}$ (Right On Right - ROR) sort of malalignment. The soccer's suffered with Unilateral Nutational stuck, $\mathrm{FR}_{\mathrm{L}} \mathrm{S}_{\mathrm{L}}$ (Right Counternutational stuck with Anticlockwise rotation - RCA), and $\mathrm{ER}_{\mathrm{L}} \mathrm{S}_{\mathrm{L}}$ (Right Nutational stuck with Anticlockwise rotation - RNA) were record least around $2.5 \%$. Soccer's who had the Unilateral Counternutational stuck and $\mathrm{ER}_{\mathrm{R}} \mathrm{S}_{\mathrm{R}}$ (Left Nutational stuck with Clockwise rotation - LNC) was observed around $5 \%$ in the aggregate presentation, and the dysfunctions with Bilateral Counternutational stuck and $\mathrm{FR}_{\mathrm{R}} \mathrm{S}_{\mathrm{R}}$ (Left Counternutational stuck with Clockwise rotation - LCC) were recorded as $7.5 \%$, and the Bilateral Nutational stuck was seen in $10 \%$ of the aggregate subjects. The $\mathrm{NR}_{R} \mathrm{~S}_{\mathrm{L}}$ (Left On Left - LOL) was the second most astounding regular sacral malalignment presentation i.e., $22.5 \%$, was seen in our study.

Table 3. Illustration shows the various workers results on Sacral malalignment assessment.

\begin{tabular}{llll}
\hline S.NO & REFERENCES & NUMBER OF SUBJECTS & METHODS OF EXAMINATION \\
\hline & & & \\
\hline & & 30 & Sacroiliac joint block \\
\hline 1 & Broadhurst and Bond & 85 & Anesthetic block of the Sacroiliac joint \\
2 & Dreyfuss et al & 16 & Normal saline and Local Anesthetic injection \\
3 & Fortin et al & 54 & Short acting Anesthetic block \\
4 & Maigne et al & 50 & Anesthetic block of the Sacroiliac joint \\
5 & Slipman et al & 40 & Simple bony palpation method \\
6 & Ganesh et al (Present Study) & $65 \%$ & $60 \%$ \\
\hline
\end{tabular}

According to Julie $\mathrm{H}$ [11], the imbalance between Multifidus and Erector spinae results in sacral instability. This was an additional proof to demonstrate the various rotational stuck of sacrum in Oblique and Antero-posterior axis. Which we were neglects to display in our previous work $[5,6]$. The present study also observed that, the instability of Multifidus and Erector spinae were results in results in Bilateral dysfunctions in Transverse axis dysfunctions. The soccer's suffered with the unilateral instability in Multifidus, Erector spinae and Piriformis were encountered with Unilateral dysfunctions in vertical axis. In our present concentrate, some additional perceptions were made that; the $\mathrm{NR}_{\mathrm{L}} \mathrm{S}_{\mathrm{R}}$ (Right On Right - ROR) and $\mathrm{NR}_{\mathrm{R}} \mathrm{S}_{\mathrm{L}}$ (Left On Left - LOL) assortment of sacral stuck will be conceivable in Oblique axis. But, the $\mathrm{FR}_{\mathrm{L}} \mathrm{S}_{\mathrm{L}}$ (Right Counternutational stuck with Anticlockwise rotation - RCA), $\mathrm{FR}_{\mathrm{R}} \mathrm{S}_{\mathrm{R}}$ (Left Counternutational stuck with Clockwise turn - LCC), $E_{\mathrm{L}} \mathrm{S}_{\mathrm{L}}$ (Right Nutational stuck with Anticlockwise revolution - RNA) and $\mathrm{ER}_{\mathrm{R}} \mathrm{S}_{\mathrm{R}}$ (Left Nutational stuck with Clockwise rotation - LNC) observational dysfunctions are conceivable only in Antero-posterior axis but not in oblique axis, which was controversies with the previous observations [20, 21, 23] Table-3.

The current perception, shows the Unilateral sacral dysfunction was typically happens in Vertical axis, which was neglects to noted by the previous workers $[3,4,7,14$, 20]. To justify our diagnosis we access the muscles of the functional slings and the muscles involved in the sacral stability. The aforementioned realities, perceptions and results demonstrated that instability in the key muscles around the Sacrum which influence the sacral stability. 


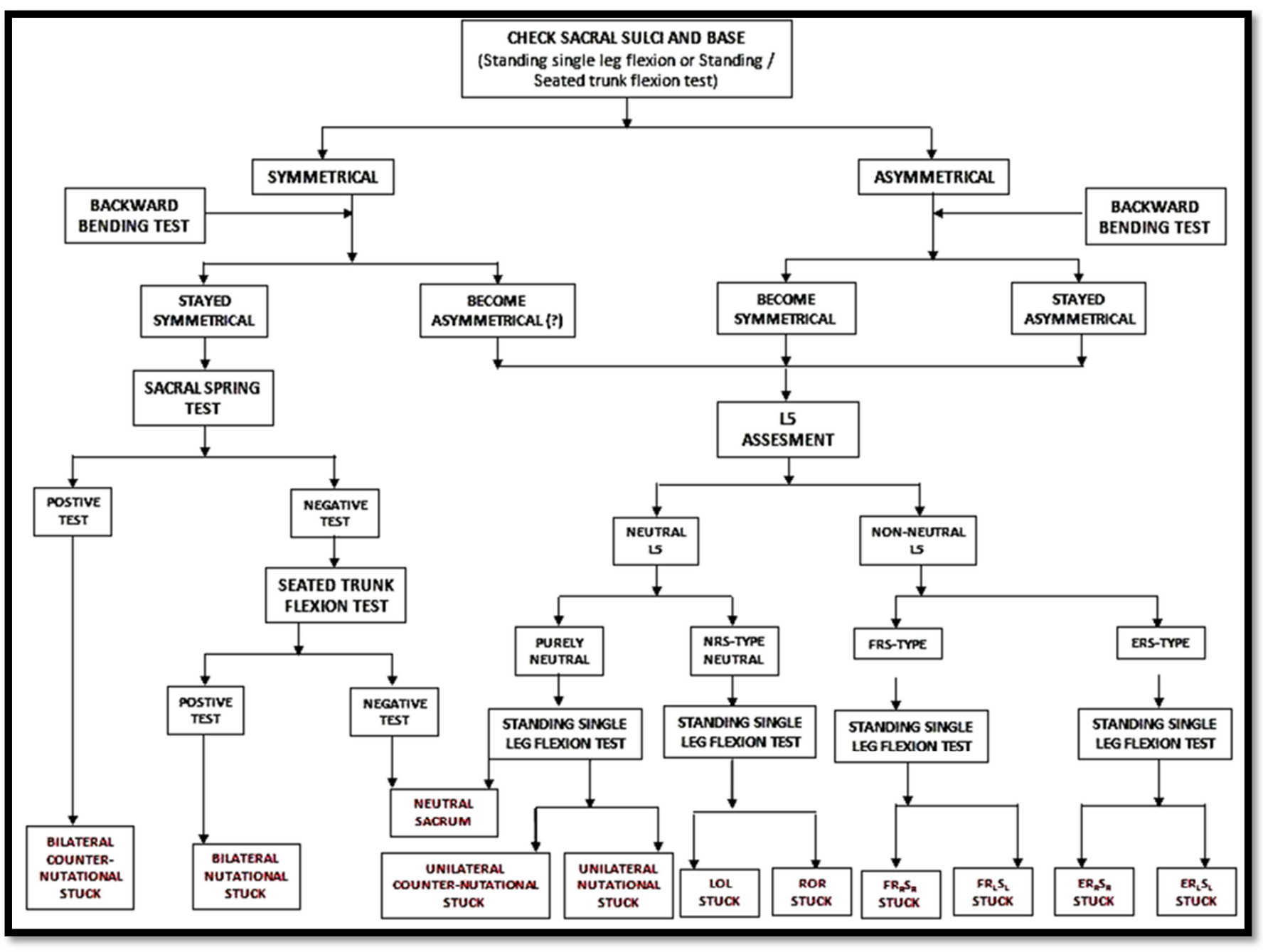

Fig. 30. Ganesh et al., Manual Sacral Assessment Chart.

\section{Conclusion}

The sacral malalignments was one of most common dysfunction in soccer players. Understanding of these 'malalignment syndrome' it is more essential to gain the knowledge of techniques used to diagnose and treat. The present study was mainly focused on the common presentations and manual diagnostic procedures of various sacral malalignments. We used simple bony palpation method to assess the various pelvic malalignments in football players. While there are many methods are available to determine the sacral symmetries, this method were very simple one and that was consistently worked well for me (Fig.-30) Table-3.

Our methods of assessing the sacral malalignments were very much useful to evaluate even the common individuals suffering with low-back or pelvis pain or dysfunction. To be masterly skilled in our current techniques of evaluation, it was more essential to locate the important bony landmarks like Sacral Sulci and Base, Infero-Lateral Angles (ILA) of the sacrum, Sacrotuberous ligament and position of L5 vertebra. The repeated measurements and assessments, makes masterly skilled in our techniques. It was not only helped to assess the "asymmetry of sacrum", also helps in the confirmation of dysfunctions presents either in "ipsilateral" or "contralateral". The outcomes were also demonstrates the irregularities in the key muscles connects with sacral stability.

In this study, we observed, $50 \%$ i.e., majority of the soccer's were suffered with oblique axis malalignments, includes ROR and LOL types of sacral dysfunctions. The players suffered with AP and Transverse axis of sacral malalignments were encountered up to $17.5 \%$ and soccer's who had the vertical axis malalignments was observed only in $7.5 \%$.

To justify our diagnosis we also accessed the muscles of the functional slings and the muscles around the bony pelvis related to the malalignment of the sacrum. The techniques were repeated in different position and also performed for two times per day and continued for fifteen days to standardize.

However, this method of assessing the sacral 
malalignments until then not documented. In this sense, the current study was mainly focused on the assessment and documentation of the different common presentations in sacral malalignments, which are most common in soccer players. This simple method of evaluation is the literature state of the art. The present study may provide the useful informations to analyze the common presentations of sacral malalignments in different sports.

Noted, the sacral malalignments are relative and it is not always necessary to know which side is the dysfunctional side if you are treating them, as you should treat both sides of the sacrum.

\section{References}

[1] Abdolhamid Daneshjoo et al., Bilateral and Unilateral Asymmetries of Isokinetic strength and Flexibility in Male Young Professional Soccer Players. Journal of Human Kinetics. 36, 45-53. 2013.

[2] Bradeley.http://www.biomechanicsacademy.com/wpcontent/u ploads/2015/07/Acritical-Review-of-the preece-Sj-2008Paper.pdf.

[3] Broadhurst NA, Bond MJ. Pain provocation test used for assessment of sacroiliac joint dysfunction. J Spinal Disorder 1998; 11: 341-345.

[4] Dreyfuss P, Dreyer S, Griffi n J et al. Positive sacroiliac screening tests in asymptomatic adults. Spine 1994; 19: 11381143 .

[5] F. P. Wedel, D. O., Evaluation and Treatment of Sacral Somatic Dysfunction. Instruction manuals published by Michel Bakker. 2013.

[6] Fernando Idoate et al., Soccer attenuates the Asymmetry of Rectus abdominis Muscle observed in Non- Athletes. PLOS ONE. 6(4), 1-7. 2011.

[7] Fortin JD, Falco FJ. The Fortin fi nger test: An indicator of sacroiliac pain. Am J Orthop 1997; 26: 477-480.

[8] Ganesh Elumalai, Malarvani Thangamani, Nirmala Palayathan, Ajit Kumar, Manish Kr Singh. Soccer Syndrome Common Presentations and Manual Diagnostic Techniques for Pelvic Malalignment Syndrome. American Journal of Sports Science. Vol. 2, No. 6, 2014, pp. 141-154.

[9] Ganesh Elumalai, Maria Declaro, Sanjoy Sanyal, Melchor Bench Bareng, Aminuddin Mohammad. Soccer Syndrome - 2: Common Innominate Malalignments and Its Manual Diagnostic Techniques in Pelvic Malalignments Syndrome.
American Journal of Sports Science. Vol. 3, No. 6, 2015, pp. 120-127.

[10] Janda V. Treatment of chronic back pain. Journal of Manual Medicine 1992; 6: 166-8.

[11] Julie H \& Warren S., Muscle imbalance among Elite Australian Rules Football Players, A longitudinal study of changes in trunk muscle size. Journal of Athletic training. 47 (3), 314-319. 2012.

[12] Kamali, F., Shokri, E., The effect of two manipulative therapy techniques and their outcome in patients with sacroiliac joint syndrome. Journal of Bodywork \& Movement Therapies, 2011.

[13] Liz Gaggini, M. A.., The asymmetric pelvis. International Association of Structural Integrators. 1-7. 2010.

[14] Maigne JY, Aivakiklis A, Pfefer F: Results of sacroiliac joint double block and value of sacroiliac pain provocation test in 54 patients with low back pain. Spine 1996; 21: 1889-1892.

[15] marchellerdc.com/pro_resources/Articles/DC_18_SI1_Shears. pdf.

[16] members.nata.org/virtuallibrary/sacroiliac/pdfs/PowerPoint_P resentations/Ilial_Pathology.pdf.

[17] Mitchell F. An Evaluation and Treatment Manual of Osteopathic Muscle Energy Techniques. Institute for Continuing Education in Osteopathic Principles, 1979.

[18] Parisien RC, Ball PA. William Jason Mixter (1880-1958). Ushering in the "dynasty of the disc." Spine Nov. 1998; 23(21): 2363-6.

[19] Pelvic Evaluation. www.waltfritz seminars.com/myofascial resource/wp content/uploads/2010/09.

[20] Slipman W. C. Sacroiliac Joint Syndrome. Pain Physician. Vol. 4(2), p 143-152, 2001.

[21] stoneathleticmedicine.com/2014/05/pelvic-upslip-androtationevaluation-and-treatment/.

[22] Warmerdam A. "Arthrokinetic Therapy: Improving Muscle Performance through Joint Mobilization." Class notes from International Federation of Orthopaedic Manipulative Therapists, Vail, Colo., 1992.

[23] White AA. Introduction. White AA, Gordon SL (eds): American Academy of Orthopaedic Surgeons Symposium on Idiopathic Low Back Pain. St. Louis, MO, CV Mosby Co. 1982, p 2. 